\title{
TAFRO syndrome presenting intrahepatic cholangitis on autopsy
}

Nishioka Hiroaki ${ }^{1}$, Shogo Nishino ${ }^{1}$, Aisa Yoshizaki $^{1}$, and Shigeo Hara ${ }^{1}$

${ }^{1}$ Kobe City Medical Center General Hospital

November 6, 2020

\begin{abstract}
Elevation of alkaline phosphatase (ALP) is reported to be an abnormal feature in TAFRO syndrome. However, the cause is unknown. Herein, we report a case of TAFRO syndrome showing intrahepatic cholangitis on autopsy, which may be the cause of ALP elevation in TAFRO syndrome.
\end{abstract}

\section{Hosted file}

CCR2020(Nishioka).pdf available at https://authorea.com/users/373567/articles/491226-tafrosyndrome-presenting-intrahepatic-cholangitis-on-autopsy

\section{Hosted file}

Figure1A(Nishioka)EJH2020.pptx available at https://authorea.com/users/373567/articles/ 491226-tafro-syndrome-presenting-intrahepatic-cholangitis-on-autopsy

\section{Hosted file}

Figure1B(Nishioka)EJH2020.pptx available at https://authorea.com/users/373567/articles/ 491226-tafro-syndrome-presenting-intrahepatic-cholangitis-on-autopsy

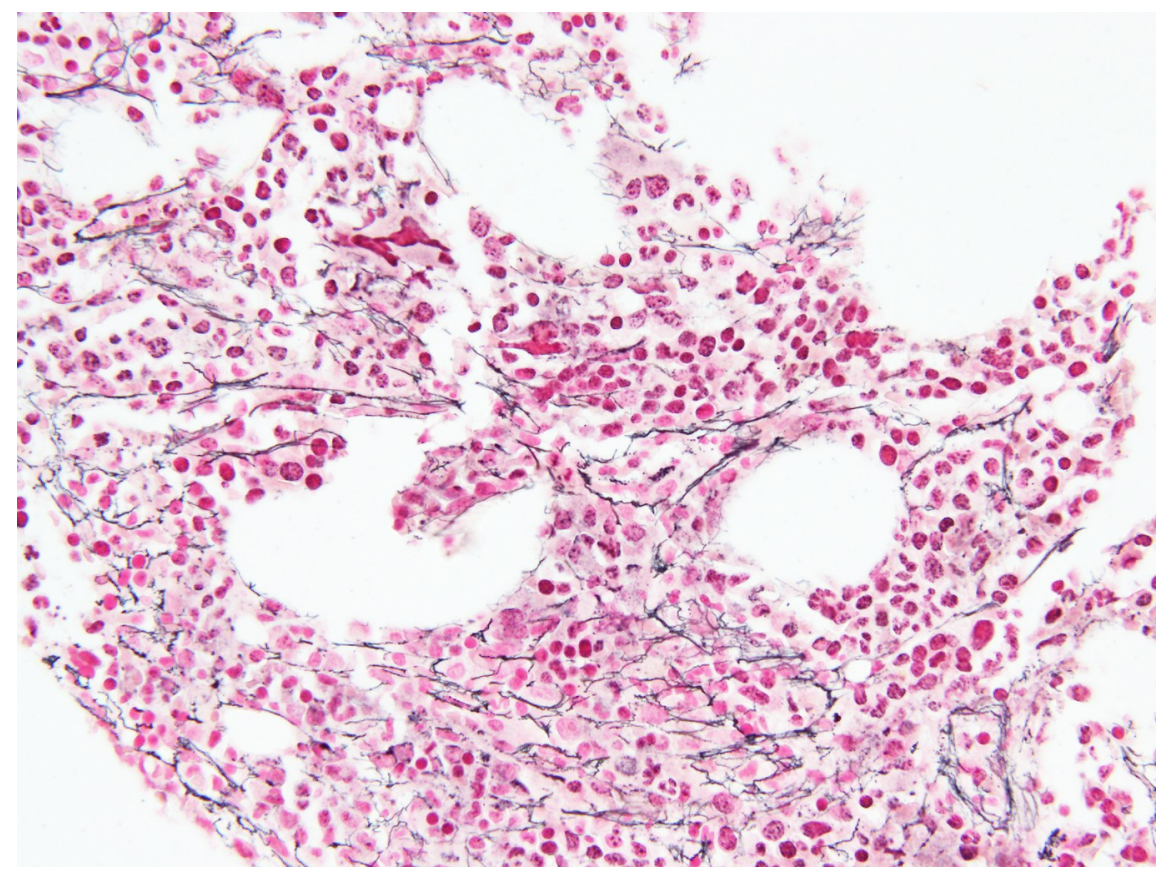




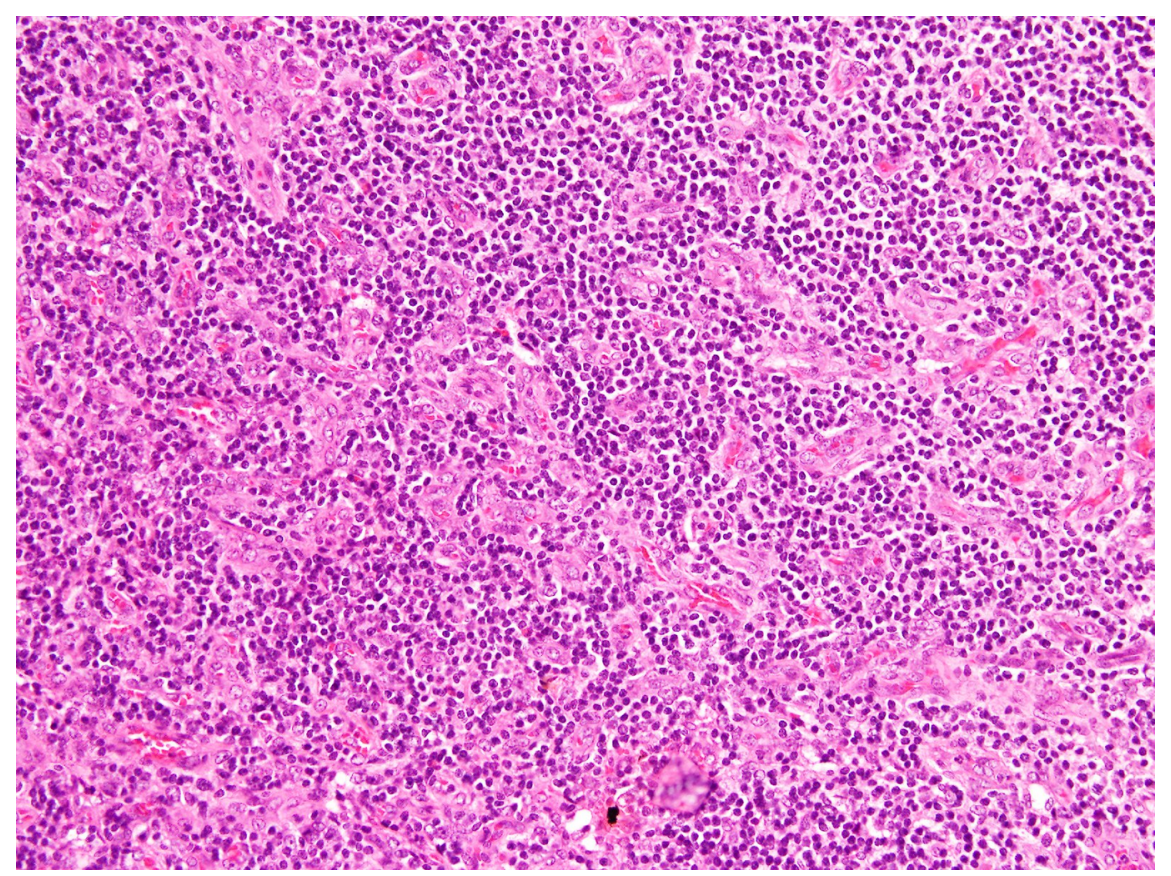

\section{Hosted file}

Figure1E(Nishioka)EJH2020.pptx available at https://authorea.com/users/373567/articles/ 491226-tafro-syndrome-presenting-intrahepatic-cholangitis-on-autopsy

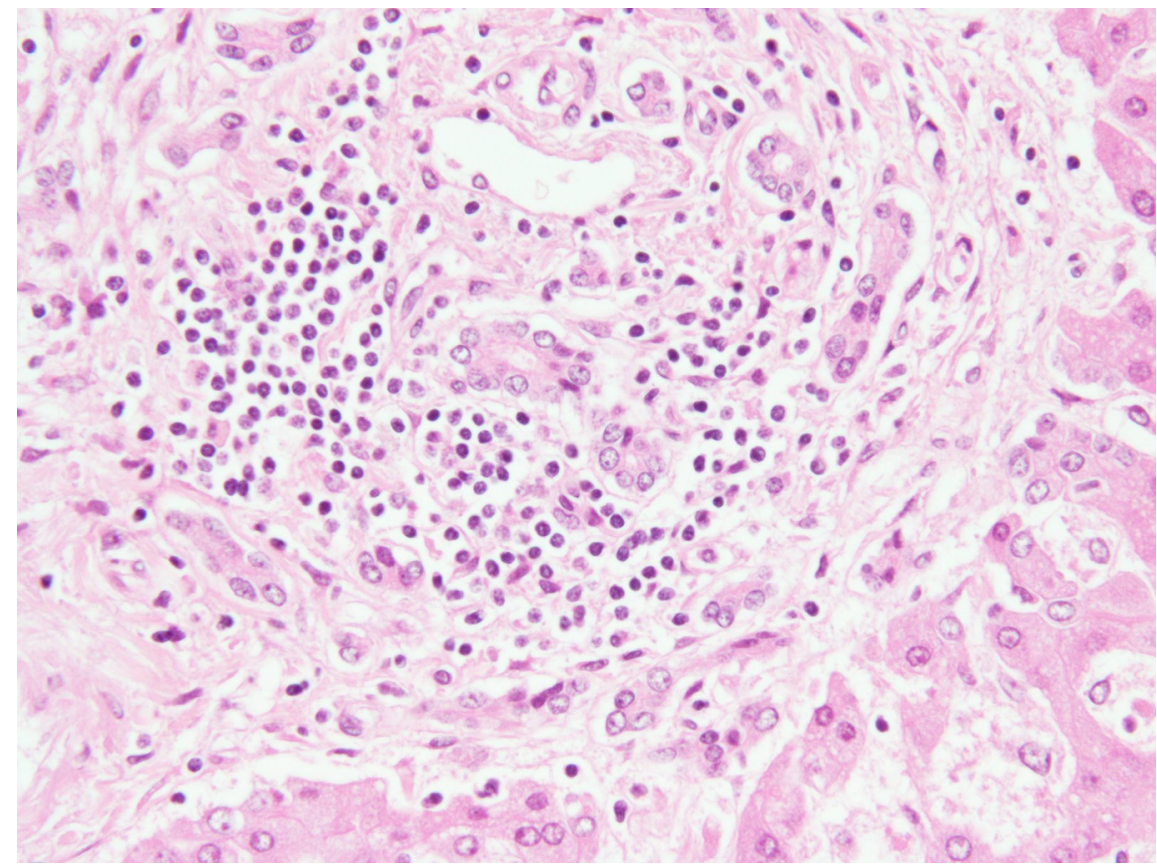



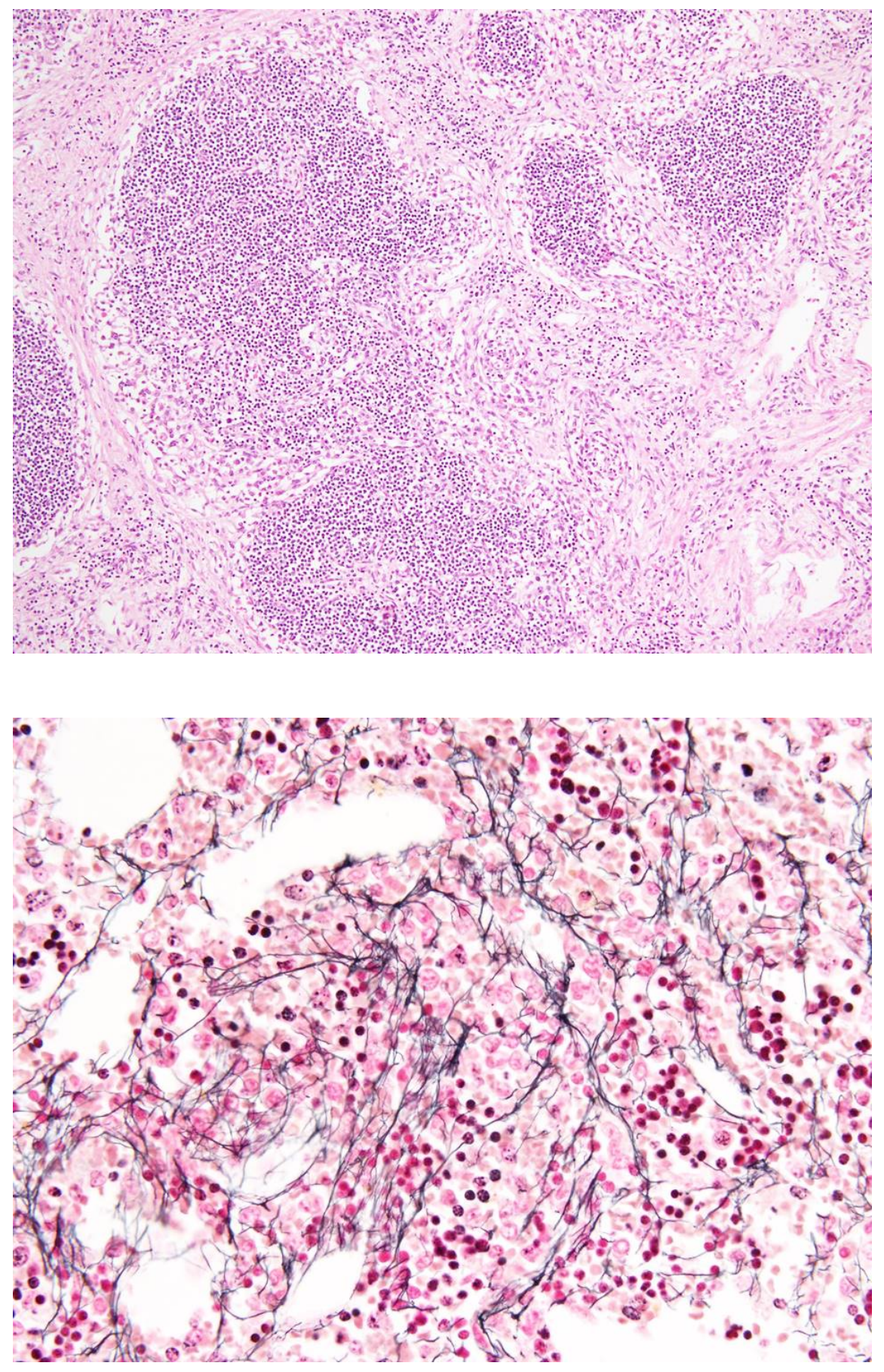

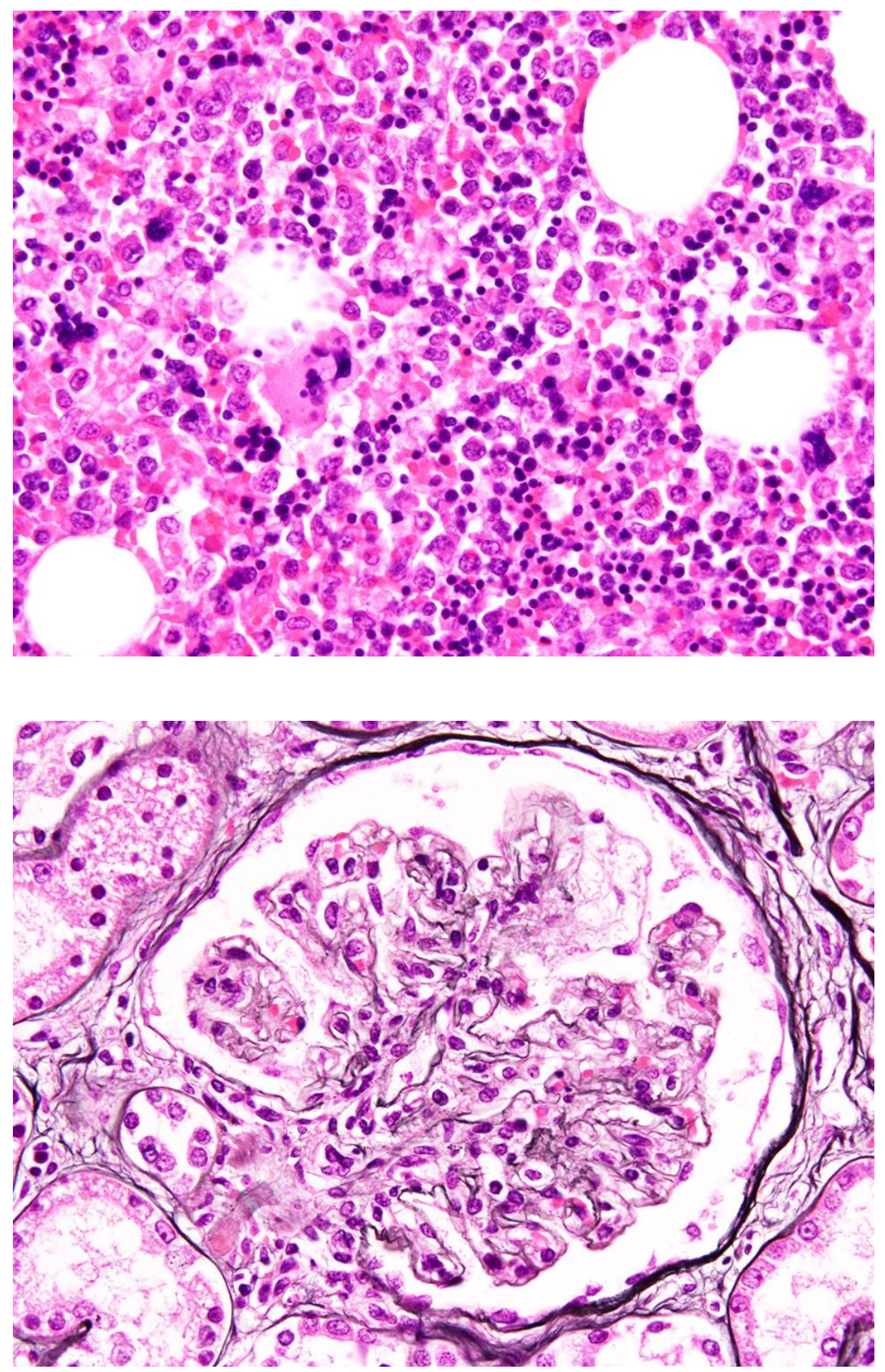


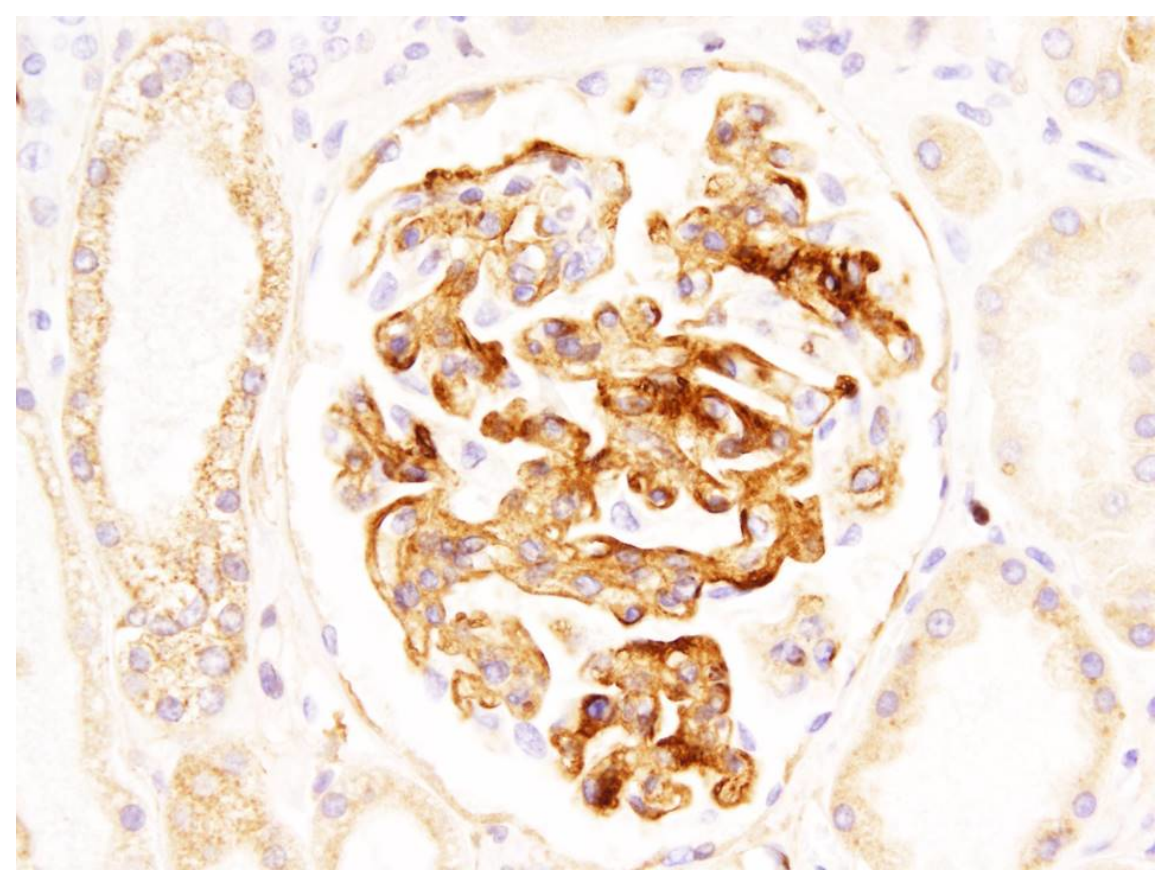

